\title{
Bahasa Indonesia bagi Penutur Asing (BIPA) Module Development Based Local Culture for Beginner
}

\author{
Sri Mulyati ${ }^{1}$ and Endang Sulistianingsih ${ }^{2}$ \\ ${ }^{1}$ Universitas Pancasakti Tegal, Indonesia \\ ${ }^{2}$ Universitas Pancasakti Tegal, Indonesia \\ ${ }^{1}$ srimulyati03@gmail.com, ${ }^{2}$ endang.sulistia@gmail.com
}

\begin{abstract}
Based on observations made by the writers, the fact that occurs in the field is that the number of Indonesian Language modules for Foreign Speakers (BIPA) is still small in number. This has become the problem underlying this research. So to solve this problem we try to develop modules as teaching material. The module was developed using a Research and Development (R\&D) study and the target of this module is beginner-level foreign speakers. This module is integrated with local culture with the aim that in addition to being proficient in Indonesian language, the users of this module will have knowledge about local culture presented in the chapters in it. Information obtained from the study are: (1) that the desired module for BIPA teachers and students is in the form of modules which contain material that uses language that is simple, easy to understand and in accordance with the beginner's ability level, (2) can provide motivation to learn, (3) ) and each chapter contains four aspects of language skills (reading, listening, speaking and writing), (4) as well as assessment that present questions related to grammar in each chapter, (5) modules are presented using selfinstructional principles and systematic, (6) graphs are presented using the principles of consistency and relevance. We recommend that further research be conducted to examines the effectiveness of the Indonesian language module for Foreign Speakers (BIPA) at the beginner level, so that the modules made can be used optimally in order to provide maximum results on learning BIPA.
\end{abstract}

Keywords: BIPA Module, Material Development, local culture, beginner

\section{PENDAHULUAN}

Peranan Bahasa Indonesia di dalam pergaulan Internasional sangatlah penting, mengingat letak Indonesia yang sangat strategis di tengah-tengah jalur perdagangan Internasional, samudera Indonesia menguhubungkan negara-negara di wilayah Asia dan samudera Pasifik menghubungkan negara-negara Asia dan Amerika. Selain menempati posisi yang strategis, Indonesia juga menempati posisi ke empat jumlah penduduk terbanyak di dunia, yaitu sekitar 267 jiwa per Juli 2019 (BPS, 2019). Alam Indonesia yang kaya akan akan Sumber Daya Alam menarik minat banyak investor untuk berinvestasi di Indonesia. Segala hal yang telah disebutkan menjadi daya Tarik tersendiri bagi orang asing untuk mempelajari Bahasa Indonesia. Tujuan mereka mempelajari Bahasa Indonesia bervariasi yaitu antara lain untuk keperluan 
bisnis, pendidikan, politik dan kebudayaan. Kebanyakan dari mereka belajar Bahasa Indonesia untuk keperluan bisnis atau kerja.

Bahasa Indonesia bagi Penutur Asing (BIPA) baru mulai dirintis sekitar tahun 1990-an dan di tahun 1999 dibentuk tim khusus untuk menangani BIPA (Bahasa Indonesia untuk Penutur Asing). Baru pada sekitar tahun 2000an BIPA mulai tumbuh dan berkembang. Supaya BIPA dapat dikembangkan secara professional dan sistematis penataan dan penelaahan secara cermat perlu dilakukan terhadap pembelajaran BIPA. Upaya yang bisa dilakukan adalah memperhatikan segala unsur yang mempengaruhi pembelajaran BIPA. Segala upaya tersebut perlu diperhatikan secara seksama, seperti manajemen kelembagaan, tenaga pengajar, sistem pengajaran, bahan ajar, media, serta hal-hal lain yang terkait dengan pembelajaran BIPA.

Hal-hal penting yang perlu dipelajari dalam pembelajaran BIPA agar pembelajaran berjalan efektif dan efisien adalah bahwa setiap tahapan pembelajaran mulai dari perencanaan, proses serta evaluasi perlu diperhatikan dan menadapatkan penangann yang khusus. Ketiga tahapan tersebut akan berlangsung dengan membuahkan hasil yang maksimal apabila didukung dengan metode/teknik mengajar yang sesuai serta dapat menumbuhkan minat serta motivasi belajar para penutur asing. Media dan bahan ajar juga tidak kalah pentingnya dalam mendukung kesuksesan pembelajaran BIPA. Pngajar atau tutor mempunyai pengaruh yang besar dalam pemilihan media dan bahan ajar. Pemilihan bahan ajar ini harus tepat sasaran sesuai dengan minat serta tingkat kemampuan pembelajar.

Bahan ajar yang baik harus memberikan gambaran terhadap penutur asing tentang keadaan atau kondisi lingkungan, social, budaya serta adat istiadat bangsa Indonesia. Dalam kaitanya belajar Bahasa asing dalam hal ini Bahasa Indonesia maka pemerolehan Bahasa (Second Language Acqutition) akan lebih mudah serta memiliki makna dan tujuan apabila konteks pembelajaran sekaligus dintegrasikan dengan budaya Bahasa yang dipelajari. Pemilihan bahan ajar yang tepat selain dapat meningkatkan keberhasilan penutur asing dalam menguasai Bahasa Indonesia juga dapat meningkatkan minat dan ketertarikan dalam mempelajari budaya Indonesia. Semakin banyak penutur asing yang tertarik untuk mempelajari Bahasa serta budaya Indonesia maka akan semakin besar peluang Indonesia untuk dikenal di dunia Internasional. Sehingga Bahasa Indonesia bisa menginternasional menjadi Bahasa resmi PBB.

Masalah yang ada saat ini terkait dengan bahan ajar BIPA adalah minim nya buku-buku yang dapat dijadikan sebagai sumber acuan yang sesuai dengan minat penutur asing. Siroj (2015) dalam penelitiannya menyebutkan bahwa tingginya minat penutur asing untuk mempelajari Bahasa Indonesia tidak diikuti dengan adanya sumber atau bahan ajar yang yang sesuai dengan minat dan tujuan mereka dalam mempelajari Bahasa Indonesia. Hal ini dibuktikan dengan langkanya buku-buku tentang pembelajaran BIPA yang tersedia di took-toko buku. Kelangkaan ini menjadi masalah yang krusial bagi pengajar BIPA. Pengajar BIPA mengalami kesulitan dalam memilih bahan ajar yang sesuai dengan kebutuhan para penutur asing karena sedikitnya pilihan yang ada. Kesulitan ini berlanjut pada kesulitan memilih materi yang tepat agar bisa mencapai tingkat kompetensi Bahasa yang diharapkan. Persoalan ini dapat diselesaikan dengan adanya pembuatan bahan ajar BIPA sebagai solusi dari tingginya minat penutur asing dalam mempelajari Bahasa Indonesia. Bahan ajar BIPA yang sesuai dengan program BIPA diharapkan dapat bisa diakses atau didapatkan dengan mudah demi kesuksesan program BIPA. Bahan ajar BIPA yang memuat budaya lokal diharapkan selain mampu meningkatkan kompetensi berbahsa Indonesia juga dapat meningkatkan pengetahuan serta kecintaan terhadap negara Indonesia.

Mustakim (2003) menyatakan bahwa tidak semua bahan ajar atau buku BIPA memberikan materi dana tau informasi tentang segala aspek social dan budaya yang ada di masyarakat Indonesia. Fakta ini dibuktikan dengan adanya 43 buku BIPA yang diteliti, ternyata hanya 
didapat 24 buku atau 56\% yang memberikan materi serta informasi tentang aspek social dan budaya masyarakat Indonesia. Sisanya sekitar $44 \%$ atau sebanyak 19 buku tidak didapat materi yang memuat aspek sosial dan budaya masyarakat Indonesia.

Beberapa analisis yang didapat dari beberapa buku BIPA, seperti buku Lentera Indonesia terbitan Pusat Perbukuan ditemukan bahwa latihan-latihan yang ada disajikan kurang memdai untuk melatih kemampuan berbicara penutur asing karena karena keterampilan berbicara dan menyimak terinegrasi hanya pada tingkat pemahaman. Kekurangan lain dari buku ini adalah bahwa Bahasa pengantar yang digunakan masih Bahasa Inggris [3]. Buku lain yang dianalisis selain buku lentera adalah buku Sehari-hari dengan Bahasa Indonesia yang dikeluarkan oleh Program Profesional Fakultas Sastra, Universitas Indonesia. Buku ini dijadikan sebagai buku sumber atau bahan ajar BIPA. Kekurangan dari buku ini adalah ilustrasi yang disajikan belum memadai serta tek-teks yang disajikan dalam buku ini panjang-panjang sehingga membuat pengguna buku ini mudah bosan untuk membacanya. Aspek social dan budaya juga kurang ditonjolkan di dalam materi-materi yang ada di buku ini.

Bahan ajar BIPA lain yang telah dinalisis adalah buku Basic Indonesian: An Introductory Coursebook yang dipublikasikan oleh Tuttle. Buku ini berisi materi yang sudah berkesesuain serta menyeluruh atau komprehensif. Kekurangan dari buku ini adalah aspek budaya belum ditonjolkan dalam buku ini. Aspek budaya dalam buku ini diberikan tidak menyatu atau tidak terintegrasi dengan latihan ataupun materi. Kekurangan lain dari buku ini adalah keseluruhan Bahasa pengantar dalam buku ini adalah Bahasa Inggris. Berdasarkan telaah analisis yang telah disebutkan dapat disimpulkan bahwa bahan ajar BIPA perlu ditingkatkan baik mutu maupun jumlahnya. Hal inilah yang mendorong peneliti untuk mengembangkan bahan ajar BIPA khususnya yang berbasis budaya lokal. Bahan ajar yang dikembangkan dalam penelitian ini berupa modul digital. Tujuan dari pengembangan modul berbasis budaya lokal adalah supaya selain penutur asing bisa mahir berbahasa Indonesia mereka juga bisa mengenal atau memperoleh pengetahuan tentang budaya-budaya yang ada di Indonesia.

Keberadaan bahan ajar mutlak diperlukan dalam pembelajaran. [4] memberikan pengertian teantang bahan ajar adalah sebagai semua bahan yang dapat dimanfaatkan guna membantu guru atau instruktur pada saat melakukan proses pembelajaran. Bahan ajar dapat berupa bahan yang tertulis maupun tidak tertulis. Bahan ajar membuat para pembelajar dapat belajar terhafdap sebuah kompetensi secara menyelurih dan sistemstis. Modul adalah bahan ajar yang dibuat secara sistematis dan terpadu dengan bahasa yang simple dan sederhana yang mudah dimengerti oleh penggunanya. Modul sengaja disusun sebagai bahan ajar yang disesuaikan dengan kebutuhan para penggunanya. Modul juga dibuat dengan menyelaraskan usia dan tingkat pengetahuan para penggunanya sehingga diharapkan para pengguna bisa belajar secara mandiri dan meminimalkan ketergantungan terhadap pengajar/tutor Dalam hal ini posisi guru atau totor hanya sebagai fasilitator.

Hal serupa dinyatakan oleh [5] yang menyebutkan bahwa modul adalah salah satu bagian dari kesatuan belajar yang disusun secara terencana untuk memberikan bantuan kepada penggunanya secara mandiri dalam rangka mencapai tujuan pembelajaran. Pengguna yang mempunyai daya serap atau tingkat pemahaman yang tinggi akan mudah menguasai materi, sementara pengguna dengan tingkat pemahaman rendah bisa mengulangi materi yang belum bisa dipahami sampai dengan benar-benar menguasai materi tersebut.

Modul yang dikembangkan dalam penelitian ini modul Bahasa Indonesia bagi Penutur Asing (BIPA) yang berbasis budaya lokal. Modul ini dikembangkan dalam bentuk digital. Pengajaran Bahasa yang diberikan di awal program BIPA mengarah pada pengajaran dengan tujuan agar dapat berkomunikasi sehari-hari. Hal ini sesuai dengan apa yang dinyatakan oleh [6] bahwa mempelajari Bahasa mempunyai tujuan tidak hanya untuk mengetahui Bahasa 
tersebut namun juga untuk memanfaatkan pengetahuan berbahasanya pada saat melakukan komunikasi di berbagai tempat dan situasi. Pengajaran BIPA ini dapat disetarakan dengan pengajaran Bahasa Inggris yang ditujukan untuk umum (General English).

Program pengajaran BIPA sampai saat ini adalah program pengajaran yang semakin berkembang. [7] dan [8] mencermati bahwa pengajaran BIPA secara khusus mulai dibahas pada Kongres Bahasa Indonesia V tahun 1988 dan terus berlanjut hingga saat ini. Hal ini menunjukkan bahwa pengajaran BIPA mempunyai potensi untuk terus dikembangan oleh isntitusi dan pengajar BIPA. [9] mengemukakan pendapatnya bahwa pengajaran Bahasa Indonesia kepada penutur asing berbeda dengan penutur asli. Karena penutubahar asing yang belajar Bahasa Indonesia memiliki Bahasa ibu serta budaya yang berbeda dengan budaya Indonesia. Pemelajar BIPA pada umumnya memiliki kepentingan tersendiri yang mengharuskan mereka untuk mempelajari Bahasa Indonesia.

Modul BIPA yang dikembangkan dalam penelitian ini dintegrasikan dengan muatan nilai budaya lokal Indonesia. Menurut [10] yang dimaksud budaya lokal adalah semua ide, aktivitas dan hasil aktivitas manusia dalam kelompok masyarakat di lokasi tertentu. Budaya lokal tersebut secara actual masih tumbuh dan berkembang dalam masyarakat serta disepakati dan dijadikan pedoman bersama. Dengan demikian sumber budaya lokal bukan hanya berupa nilai, aktivitas dan hasil aktifitas tradisional atau warisan nenek moyang masyarakat setempat, namun juga semua komponen atau unsur budaya yang berlaku dalam masyarakat serta menjadi ciri khas dana tau hanya berkembang dalam masyarakat tertentu. Budaya lokal yang dimaksud dalam penelitian ini adalah segala bentuk cipta, rasa dan karsa yang berkembang di masyarakat. Peneliti berasal dari kota Tegal yang wilayahnya ada di Propinsi Jawa Tengah, Indonesia. Budaya yang diangkat dalam pengembangan modul ini adalah budaya khas Tegal, seperti kesenian balo-balo dan tari topeng endel [11].

\section{METODE PENELITIAN}

Penelitian ini menggunakan desain yang dikembangkan oleh Borg dan Gall dan telah dimodifikasi oleh peneliti. Metode yang digunakan adalah Research and Development $(R \& D)$ dimana dalam penelitian ini dihasilkan sebuah produk tertentu serta diadakan pengujian terhadap efektivtias produk tersebut. Dalam pengujian produk diambil beberapa langkahlangkah yaiutu: (1) potensi dan masalah, (2) pengumpulan data, (3) desain produk, (4) validasi desain, (5) revisi desain, (6) uji coba produk, (7) revisi produk, (8) uji coba pemakaian, (9) revisi produk, dan (10) produksi masal.

Dalam mengembangkan modul sebagai bahan ajar, peneliti memberikan penyesuaian melalui pembatasan tahap-tahap yang digunakan. Dalam hal ini peneliti hanya memakai 5 tahapan dalam mengembangkan produknya. Tahapan yang diambil dalam penelitian ini hanya sampai pada tahap revisi/perbaikan desain setelah desain yang dihasilkan divalidasi oleh para ahli. Penelitian ini diselesaikan hanya dalam skala terbatas, dimana baik angket kebutuhan maupun uji validasinya nya dilakukan pereduksian. Meskipun peneliti melakukan pereduksian kualitas Research and Development $(R \& D)$ yang dilakukan tetap terjaga kualitasnya. Kajian dalam penelitian ini adalah bahan ajar BIPA yang berbasis budaya lokal bagi penutur asing tingkat pemula.

\section{HASIL DAN PEMBAHASAN}

Penelitian ini menggunakan angket dalam menganalisis kebutu han modul BIPA berbasis budaya lokal untuk penutur asing tingkat pemula. Angket dibagi menjadi dua golongan yaitu 
(1) angket berbasis kebutuhan dalam pengembangan modul BIPA berdasarkan pemahaman penutur asing dan (2) angket yang didasari oleh kebutuhan bahan ajar berdasarkan pemahaman pengajar BIPA. Karakteristik pengembangan bahan ajar dalam penelitian ini dirumuskan melalui hasil analis terhadap angket.

Pada bagian kurikulum pembelajaran BIPA dilakukan analisis. Analisis ini berupa angket kebutuhan menurut pemahaman pengajar BIPA yang memuat parameter kompetensi yang digunakan dalam kelas BIPA untuk tingkat pemula. Pada parameter ini, pengajar atau tutor BIPA diberi pilihan jawaban yang berupa segala kompetensi di dalam silabus BIPA di tingkat pemula A1. Di dalam silabus BIPA tingkat pemula A1 untuk penutur asing terdapat kompetensi yang terdiri dari: (1) dapat memperkenalkan diri dan orang lain, (2) dapat menanyakan dan manjawab pertanyaan terkait informasi seseorang, sebagai contoh: tempat tinggal, orang yang dikenalnya, dan sesuatu yang dimilikinya, (3) dapat memahami serta menggunakan ungkapan sehari-hari yang sering digunakan, dan (4) dapat memahami serta menggunakan ungkapan yang tergolong sangat dasar untuk kepuasan atau kebutuhan yang konkrit. Hasil dari analisis angket kebutuhan menampakan bahwa kesemua pengajar BIPA menginginkan supaya bahan ajar dalam hal ini modul yang dikembangkan oleh peneliti memuat semuat kompetensi yang terdapat dalam silabus BIPA tingkat pemula A1.

Prototipe bahan ajar dalam hal ini modul dibuat dan dikembangkan berdasarkan karakteristik dan prinsip pengembangan (development) bahan ajar. Prototipe ini secara garis besar digolongkan menjadi lima bagian yang terdiri dari: (1) bentuk fisik, (b) sampul buku, (c) muatan isi/materi inti, (d) materi pelengkap, dan (e) evaluasi. Di dalam aspek isi/materi pengembangan bahan ajar dilandaskan pada prinsip-prinsip relevansi, kecukupan, adaptif serta inovatif. Pengembangan bahan ajar pada aspek penyajian mengacu pada prinsip self instructional atau pembelajaran mandiri serta sistematis. Dalam aspek Bahasa dan keterbacaan prinsip yang digunakan adalah konsistensi, adaptif serta relevansi. Selanjutnya, aspek kegrafikan memanfaatkan prinsip konsistensi dan relevansi.

Para ahli dan pengajar BIPA memberikan penilaian dan saran terhadap modul yang dikembangkan oleh peneliti. Penilaian dan saran ini didasarkan kepada empat aspek utama dalam bahan ajar. Hasil dari penilaian tersebut adalah: (1) perwajahan/kegrafikan mendapatkan nilai 80,95 dari pengajar BIPA dan 92,85 dari ahli, (2) isi/materi mendapatkan hasil 80,95 dari pengajar BIPA dan 85,71 dari ahli, (3) Bahasa dan keterbacaan mendapatkan nilai 84, 99 dari pengajar BIPA dan 77,5 dari ahli. Saran yang diberikan oleh para ahli dan pengajar BIPA membuahkan hasil berupa perbaikan terhadap enam aspek yang meliputi: (1) penambahan pelafalan huruf dan juga diftong, (2) pemilihan diksi, (3) format latihan, (4) muatan budaya lokal (Tegal), (5) substansi tata Bahasa, dan (6) komposisi atau tata letak.

\section{SIMPULAN}

Berdasarkan penelitian yang dilakukan oleh tim peneliti maka dapat diambil kesimpulan bahwa para pelajar BIPA memerlukan penyegaran dari bahan ajar yang telah tersedia. Bahan ajar berupa modul BIPA yang dintegrasikan dengan muatan buadaya lokal mendapatkan respon positif dari penggunanya.

\section{REFERENCES}

[1] M. B. Siroj, "Pengembangan Model Integratif Bahan Ajar Bahasa Indonesia Ranah Sosial Budaya Berbasis ICT bagi Penutur Asing Tingkat Menengah," J. Pendidik. Bhs. 
dan Sastra Indones., vol. 4, no. 2, 2015.

[2] Mustakim, "Peranan Unsur Sosial Budaya dalam Pengajaran BIPA," in Konferensi Internasional Pengajaran Bahasa Indonesia bagi Penutur Asing IV, 2003.

[3] D. Subektiningsih, "Analisis Latihan-latihan dalam Buku Teks BIPA Lentera Indonesia," SKRIPSI Jur. Sastra Indones. Sastra UM, 2009.

[4] A. Majid, "Perencanaan pembelajaran mengembangkan standar kompetensi guru," Bandung PT. Remaja Rosdakarya, 2008.

[5] Sukiman, Pengembangan Media Pembelajaran. Yogyakarta: Pustaka Insan, 2011.

[6] I. Suyitno, "Pengembangan Bahan Ajar Bahasa Indonesia untuk Penutur Asing (BIPA) berdasarkan Hasil Analisis Kebutuhan Belajar," Wacana, vol. 9, no. 1, pp. 62-78, 2007.

[7] A. C. Alwasilah and K. A. Harras, "Prosiding Konferensi Internasional Pengajaran Bahasa Indonesia bagi Penutur Asing (KIPBIPA) III," Bandung: Andir, 2000.

[8] Y. Mulyati, "MENGOKOHKAN JATIDIRI BANGSA MELALUI PROGRAM BIPA BERBASIS BUDAYA," Tersedia file. upi. edu/... YETI MULYATI/MAKALAH BIPA. $p d f$, vol. 19, 2011.

[9] A. Rofiuddin, Pendidikan Bahasa dan Sastra Indonesia di Kelas Tinggi. Malang: Universitas Negeri Malang, 2001.

[10] D. Sutarto, "Kearifan budaya lokal dalam pengutan tradisi malemang di tengah masyarakat modernisasi di Sungai Keruh Musi Banyuasin Sumatera Selatan," $J$. Dimens., vol. 5, no. 3, 2016.

[11] K. Saddhono, "Integrating culture in Indonesian language learning for foreign speakers at Indonesian universities," J. Lang. Lit., vol. 6, no. 2, 2015. 